\title{
The views and knowledge of parents of children with autism spectrum disorder on a range of treatments
}

\author{
V Wetherston, BCom Path (SLP), MSLT; S Gangat, BCom Path (SLP); N Shange, BCom Path (SLP); \\ K Wheeler, BCom Path (SLP); S B Sayed Karrim, MCom Path (SLP); J Pahl, BSc, MA, Dip Ed \\ Discipline of Speech-Language Pathology, School of Health Sciences, University of KwaZulu-Natal, Durban, South Africa
}

Corresponding author: J Pahl (pahlj@ukzn.ac.za)

\begin{abstract}
Background. Autism spectrum disorder (ASD) is a neurodevelopmental disorder that appears before the age of 3 years. Symptoms reflect delayed or abnormal social interaction and communication skills, with restricted or repetitive behaviour warranting the need for early intensive treatment. Methods. The aim of the study was to investigate the knowledge and views of parents regarding treatments for their children, aged between 5 and 9 years old with ASD, in eThekwini Metropolitan Municipality, South Africa. An embedded mixed methods research design was utilised. Nonrandom purposive sampling was used to select 46 parents of children with ASD. A 42-item questionnaire was used and the data were interpreted using descriptive statistics and thematic analysis.

Results. More than half of the parents (53\%) were unfamiliar with or had only heard of treatments in question, while $13.4 \%$ had a practical understanding of the treatments. Of all the treatments, parents rated their knowledge of speech-language therapy (SLT) most highly. The majority (68\%) stated that they had difficulties accessing ASD treatment facilities and healthcare professionals, and perceived treatments as being costly. Even so, $74 \%$ of parents reported that they had a good relationship with their healthcare professional.

Conclusion. The above findings should be viewed as motivation for health professionals to share information regarding the range of ASD treatments. They can assist parents in accessing appropriate facilities, recommend treatments that are supported by research, and update their knowledge on advances in ASD treatment.
\end{abstract}

S Afr J Child Health 2017;11(3):117-121. DOI:10.7196/SAJCH.2017.v11i3.1274

Autism spectrum disorder (ASD) is a severe, lifelong neurodevelopmental condition without a cure. In a plethora of available and new treatments there is no exclusively accepted treatment. The variability and severity of symptoms differ widely between children with ASD, and over time, treatments advised by professionals have varied. Therefore, it is imperative that parents collaborate with health professionals to select and design treatment programmes. Parents of children with ASD can provide significant data on the effects of a wide variety of treatments. Parents need accurate knowledge of the treatments, as they play a vital role in selecting and implementing them. This is done by the health professionals who provide counselling and information to the parents about available and evidence-based treatments.

In this study, treatment was defined as any medical or therapeutic intervention for children with ASD. The Diagnostic and Statistical Manual of Mental Disorders - IV was used to describe the characteristics and diagnostic criteria of the children in this study. ${ }^{[1]}$ Two overlapping categories of treatment were used in this study. The first grouping is in accordance with the National Standards Report, which was in operation at the time of the study, where treatment is classified according to its evidence basis as established, emerging or unestablished. ${ }^{[2]}$

Established treatments are treatments for which there is evidence of a beneficial effect. ${ }^{[2]}$ Examples of established treatments include pivotal response training, discrete trial instruction, functional communication training and social stories. Emerging treatments are those supported by one or more studies that suggest the intervention may produce positive outcomes; however, not enough studies have consistently shown these benefits. ${ }^{[2]}$ Treatments such as augmentative and alternative communication, picture exchange communication system (PECS), and developmental, individual differences and relationship-based model (DIR)/floortime, are classified as emerging treatments. As there is no evidence to support the success of the aforementioned treatments, they are referred to as unestablished treatments.
Studies do not report ineffective or harmful treatments as researchers tend to change the focus of their studies to treatments which may be effective as soon as they suspect a treatment to be harmful or ineffective. ${ }^{[2]}$

The second category of ASD treatments comprised developmental approaches, naturalistic behavioural approaches and controversial and alternative medicines. Developmental approaches comprise a combination of features, such as focusing interventions on the impairments associated with ASD, e.g. impairments in social interaction, verbal and nonverbal communication, and behaviour. Other features focus on including the family in decision-making and ensuring that interventions are based on the family's requirements, concerns and priorities, ensuring that intervention occurs within natural environments and providing intervention through natural methods. ${ }^{[3]}$ Examples of developmental approaches include DIR/floortime, ${ }^{[4]}$ and relationship development intervention. ${ }^{[5]}$ Behavioural interventions are based on operant conditioning techniques to facilitate learning. Examples include naturalistic behavioural approaches, which contain features such as following the child's lead, providing intervention in natural environments and the use of highly motivating rewards. ${ }^{[6]}$ Other treatments are based on the principles of applied behavioural analysis (ABA), such as pivotal response training and incidental teaching. Other behavioural approaches include milieu teaching, intensive behaviour intervention or early behaviour intervention. Intensive behaviour intervention, uses $\mathrm{ABA}$ techniques to improve socialisation and communication skills. ${ }^{[7,8]}$ Some treatments do not fall into the above categories. They address specific aspects such as social interaction and communication. Examples of these treatments include speech-language therapy (SLT) and augmentative and alternate communication. Controversial and alternative medicines (CAM) are classified as unestablished treatments. ${ }^{[2]}$ Children who participate in CAM interventions usually do so in conjunction with a more conventional therapy, e.g. behavioural and educational services. ${ }^{[9]}$ 
Common types of CAM include sensory motor therapies like sensory integration therapy, and certain other forms like vitamin therapies, weighted vests, chelation therapy and special diets. ${ }^{[10]}$

With the number of interventions discussed above, the role of the parent or caregiver in treatment is vital for continuity in the home context as many autism interventions take place at a therapist's office or at school. With training, families can extend SLT, occupational, and physical therapies in the home setting, with involvement in goal setting, being part of the team, helping to deliver the programme and being part of the programme evaluation. ${ }^{[11]}$ Research has shown that parent involvement increases the effectiveness of the treatment over time. ${ }^{[12]}$

Parents of children with ASD believed that treatments were costly and inaccessible. It was found that there was a lack of skilled professionals in the area of ASD and this affected parents' experiences and access to quality treatment. ${ }^{[13]}$ Long waiting lists for accessing services, lack of government support to cover costly treatment and participating in numerous treatments are tiresome. ${ }^{[14]}$ While research has shown that intensive early intervention ( $<3$ years old) has significantly improved outcomes, these services can be extremely expensive. ${ }^{[14-16]}$ Children with ASD are often required to participate in a number of different treatments, which can be time consuming and costly. Relationships with healthcare professionals can be difficult and it has been found that most parents have negative feelings towards their healthcare professional. ${ }^{[17]}$ Parents felt as though healthcare professionals did not share the parents' concerns in treatment of ASD and did not use 'the information that parents provided in a collaborative nature. ${ }^{\text {, }}{ }^{18]}$

\section{Rationale for the study}

Parents of children with ASD often manage a complex array of treatments and therapies for their children. ${ }^{[17]}$ Little is known about parents' satisfaction with the treatments and they may withdraw their child from treatment if no progress is observed ${ }^{[1,20]}$ In addition, in South Africa (SA) the treatment needs of children with ASD are not met. ${ }^{[21]}$ Further, Deyro et $a l .^{[22]}$ found professional advice to be the most influential source in guiding parents in ASD treatment selection for their children. It is therefore important for health professionals to take parents' views into account when suggesting treatments by sharing knowledge or increasing awareness of the treatments available and understanding the parents' views to improve the quality of services. ${ }^{[23]}$ Furthermore, there is little research in the area of parents' views and knowledge of treatment for children with ASD in SA.

\section{Context}

This study was conducted in the eThekwini Metropolitan Municipality of KwaZulu-Natal Province (KZN), SA. eThekwini is one of 11 districts in KZN with an estimated population of 3090 126, the majority of whom speak isiZulu. ${ }^{[24]}$ As ASD is not associated with culture, socioeconomic status or geographical region, the ASD prevalence statistics of 1:68 are taken to apply to SA. ${ }^{[25]}$ In SA, services for ASD are obtained from governmental sources, via the Department of Health, for children between 0 and 6 years old; certain special schools treat children from 6 years to 18 years old, and the private healthcare industry and education services support families with medical aid (insurance) or sufficient funds. There is no set policy or set of guidelines for the identification and management of children with ASD. There is also a paucity of recordkeeping or database management of children with ASD in KwaZuluNatal.

\section{Methods \\ Study design}

A mixed methodology was used with an embedded research design.

\section{Study participants}

A non-random purposive sampling technique was used to recruit parents or caregivers of children with a diagnosis of ASD in the eThekwini district in KZN. Parents were recruited via schools or centres who offer placement for children with ASD, via speech-language therapists, and via ASD support group co-ordinators. Children were required to be 5 - 9 years old, have no co-occurring syndromes, have received or were currently receiving treatment for ASD for a minimum of 6 months.

The participants included 40 mothers and 6 fathers. The median age of their children was 7 years, 1 month old. Their children fell into different ethnic groups, which included 19 black, 18 indian, 7 white, 1 asian, and 1 coloured. The majority (67\%) of the children were English first-language speakers; 15 children were isiZulu first-language speakers. The median age of diagnosis was 3 years, 6 months old.

\section{Data collection}

Data were obtained using a questionnaire, which was either paper-based or electronic (sent via e-mail). The first 30 questions pertained to the participants' knowledge of treatments on an ordinal five-point Likert scale, developed and expanded from a questionnaire by Sansosti. ${ }^{[18]}$ The next 12 questions pertained to the views that participants had about these treatments. A pilot study was conducted with two parents of children with ASD. Minor adjustments were made to the layout of the questionnaire following the pilot study.

\section{Analysis}

Quantitative data were analysed using the Statistical Package for Social Sciences (SPSS) version 21.0 (IBM Corp., USA) and thematic analysis. Qualitative data were analysed by reviewing open-ended questions and noting emerging themes.

\section{Reliability, validity and trustworthiness}

Reliability and validity were addressed by ensuring that all participants met the inclusion criteria; that data were collected, analysed, represented and interpreted in the same manner, using the same data collection instrument. A thorough description of the research context and any assumptions that were central to the research were recorded so that they could be applied to the greater population. In terms of credibility, a sample that reflected the range of ethnicities and languages of the eThekwini district was obtained.

\section{Ethical issues}

Ethical clearance was obtained from the relevant university ethics committee (ref. no. SHSEC 047/13). The principles of ethical clearance, protection from harm, informed consent, confidentiality, the right to privacy and data management were considered.

\section{Results and discussion Parents' knowledge of the different treatments}

Of all the treatments used, 53.3\% were rated as being unfamiliar or just heard of (Fig. 1). A third of the treatments were rated as being familiar, with a limited understanding of the treatment. The parents indicated that they had a practical understanding of only $13.4 \%$ of the treatments.

The five treatment options that parents rated themselves most knowledgeable in were SLT, physiotherapy, occupational therapy, parentinvolvement and social stories. It was not surprising that SLT was well known, as it addresses core deficits in ASD. ${ }^{[18,26,27]}$ The first three treatments would be offered in special schools and at hospitals in SA, also contributing to parents' knowledge of them.

The data indicated that $78.2 \%$ of parents were not informed about the different treatment options prior to use of the treatment (Fig. 2). Families indicated a belief that professionals themselves are not informed about the range of ASD treatments. This could indicate a lack of guidance from professionals regarding which treatments to select. ${ }^{[18]}$

\section{Parents' access to treatments}

Most of the participants (68.6\%) stated that they had difficulty accessing treatment facilities and health professionals specialising in 


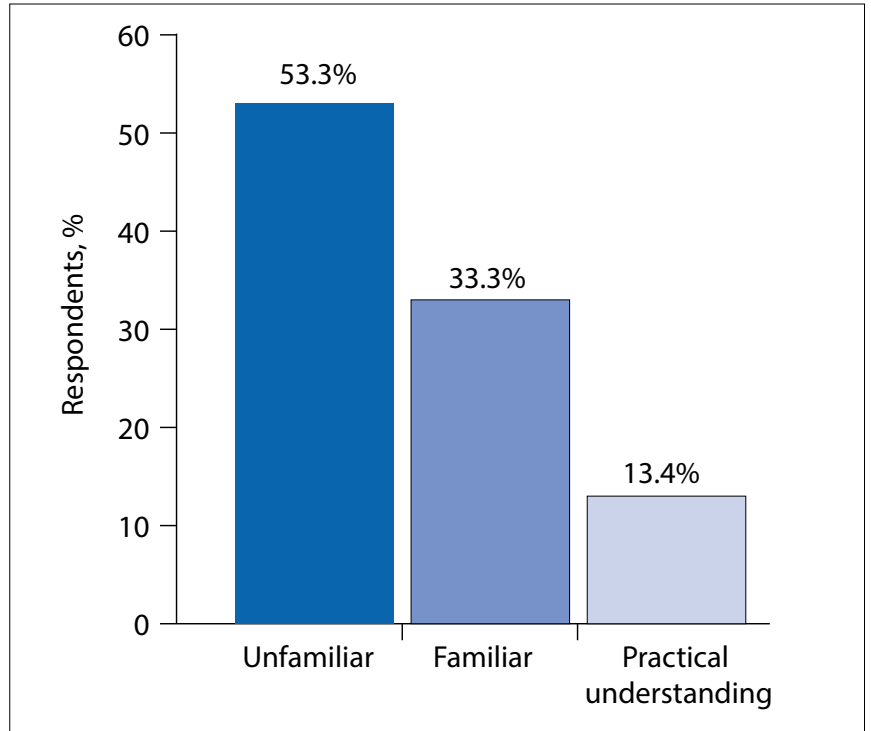

Fig. 1. Level of knowlegde of treatments $(N=46)$.

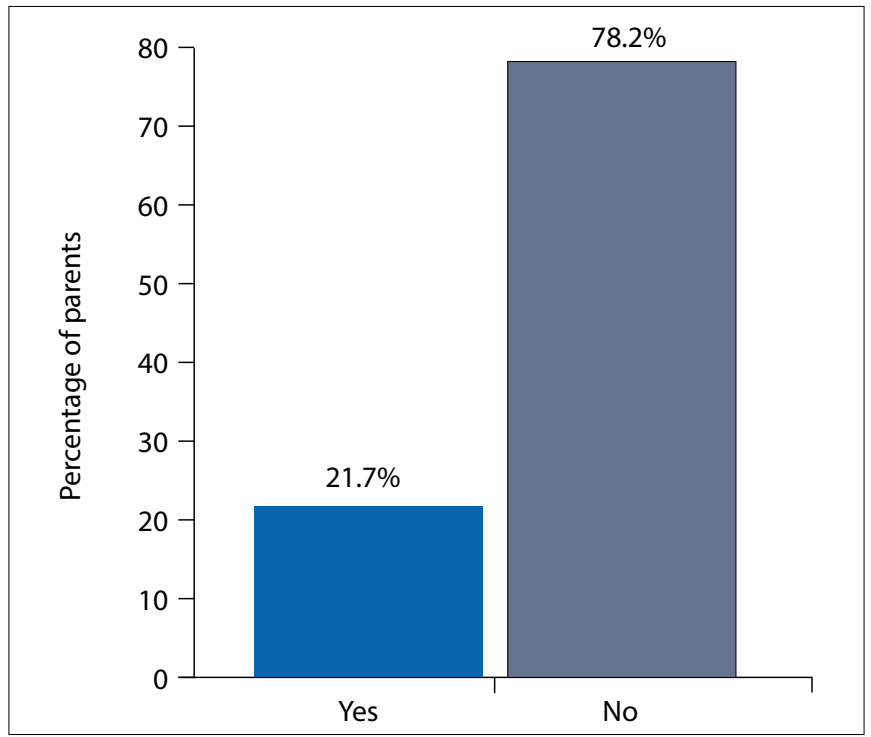

Fig. 2. Number of parents who were informed of the various treatments prior to the use of the chosen treatment $(\mathrm{N}=46)$.

ASD (Fig. 3). These findings correlate with a study of participants from the USA, Canada, Australia, New Zealand, England and Ireland. ${ }^{[14]}$

Challenges included limited numbers of trained health professionals and treatment facilities, long waiting lists and long distances travelled by parents to receive treatment. One parent stated that 'there is so much on the internet yet so few treatments are available in SA'. Another parent mentioned that 'it is extremely hard to find one (a treatment) in your mother (home) language'. In SA, the commonly used treatments were traditional therapies such as SLT and occupational therapy, applied behavioural analysis, dietary and biomedical interventions. Many of these treatments are only available in the private sector.

\section{The cost involved in various treatments as perceived by} the parents

The data showed that $73.6 \%$ of parents felt that the treatments for ASD were costly (Fig. 4). This parallels previous research where parents stated that services for ASD can be extremely expensive and that there is a lack of government support. A parent declared that it is very expensive and there is no government funding for external (out of school) therapy and

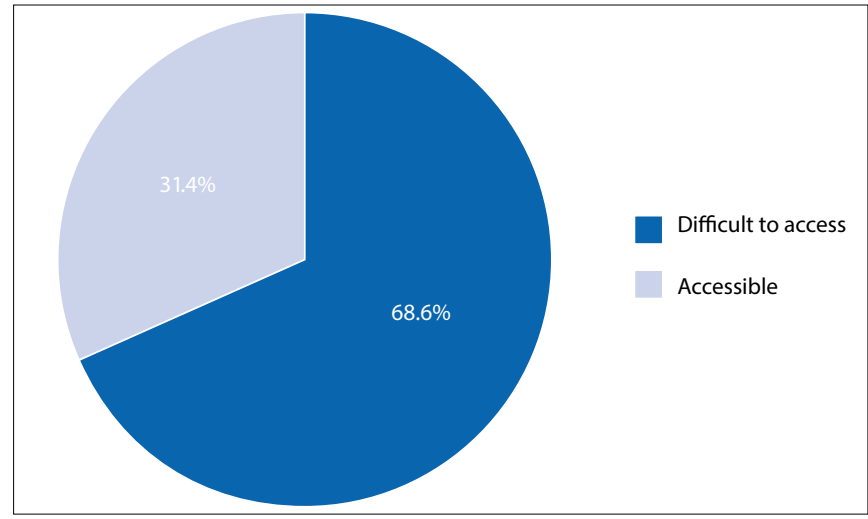

Fig. 3. Parents' access to treatment $(\mathrm{N}=35)$.

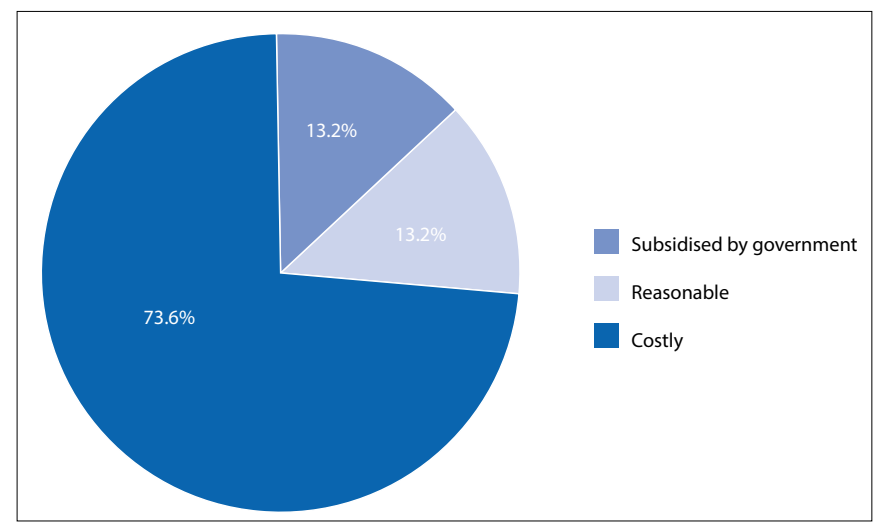

Fig. 4. Costs involved in treatment for autistic spectrum disorder (ASD) as perceived by the parents $(\mathrm{N}=38)$.

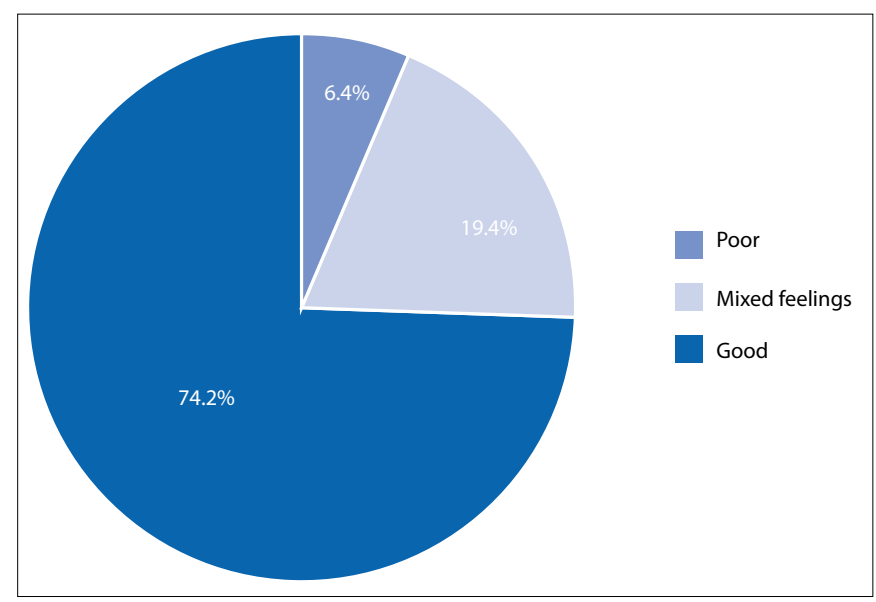

Fig. 5. Parents' relationship with healthcare professionals $(\mathrm{N}=31)$.

medical aid does not cover most of the costs as autism is not recognised as a primary medical benefit.' Parents (13.2\%) who received government subsidised treatment from schools or hospitals reported that the costs of the treatments were reasonable. Accessing school-based services is consistent with reports by Patten et al. ${ }^{[27]}$ and Mire et al. ${ }^{[28]}$

\section{Parents' perspective on the effectiveness of treatments}

As found previously, a third of parents believed that a combination of treatments had the best outcomes in their children. ${ }^{[1726]}$ According to $43.6 \%$ of participants SLT was the most effective treatment for their child. For example, one parent reported that SLT was effective as it gave my child confidence and encouragement when it came to attempting new words both in home language isiZulu and English.' Another parent stated that 'before speech therapy my son could not talk at all, now he is 


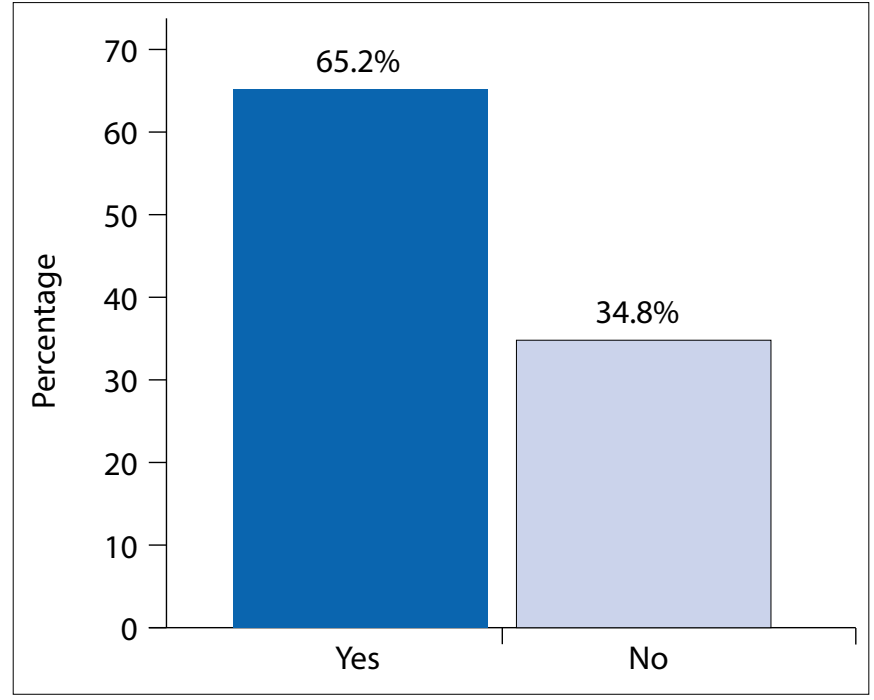

Fig. 6. Family involvement in the treatment $(\mathrm{N}=46)$.

saying a few words, which I can understand, where before he was only pointing at things.'

Other treatments that parents found effective included applied behaviour analysis $(28.2 \%)$, occupational therapy $(25.6 \%)$, augmentative and alternative communication (18\%), and drug therapies (12.8\%). The use of drug therapies could be linked to the high rate of comorbidity. ${ }^{[29]}$ There were mixed views on the use of CAM treatments and some parents perceived these to be most effective, despite the lack of evidence to support them, e.g. chelation therapy and a gluten-free, casein-free diet. A previous study supported these findings. ${ }^{\left[{ }^{[0]}\right.}$ According to $69 \%$ of participants, the reason for ending the use of a particular treatment was because the treatment was ineffective.

\section{Parents' relationship with service providers}

Contrary to previous research, which found that that most parents had negative feelings towards their health professionals, this study found that $74.2 \%$ parents had a good relationship with their health professional (Fig. 5) ${ }^{[17]}$ This was due to good communication between the health professionals and the parents, the health professionals' willingness to assist where needed, health professionals working as a team with the parents, and parents feeling that they were constantly aware of what was occurring in treatment.

Parents (6.4\%) who viewed their relationship with their healthcare professional as being poor, commented on a lack of communication and reluctance to help, inappropriate recommendations and a lack of individual care. The remaining $19.4 \%$ experienced mixed feelings regarding their relationship with professionals.

\section{Families' involvement in the treatment process}

Nearly two-thirds of parents $(65.2 \%)$ indicated that their families were involved in treatment by facilitating treatment, providing transport, support and encouragement, and in decision-making (Figs 6 and 7).

\section{Study limitations}

Limitations include a small sample size due to the low response rate. The results are only representative of one geographic location and all of the information was provided from the parents by self-report. The questionnaire measured the parents' perception of their knowledge rather than their actual knowledge and the researchers were speech-language therapists which could have impacted parents' response to SLT-related questions.

\section{Conclusion}

Parents of children with ASD in eThekwini have some degree of knowledge of the different treatments available. The findings

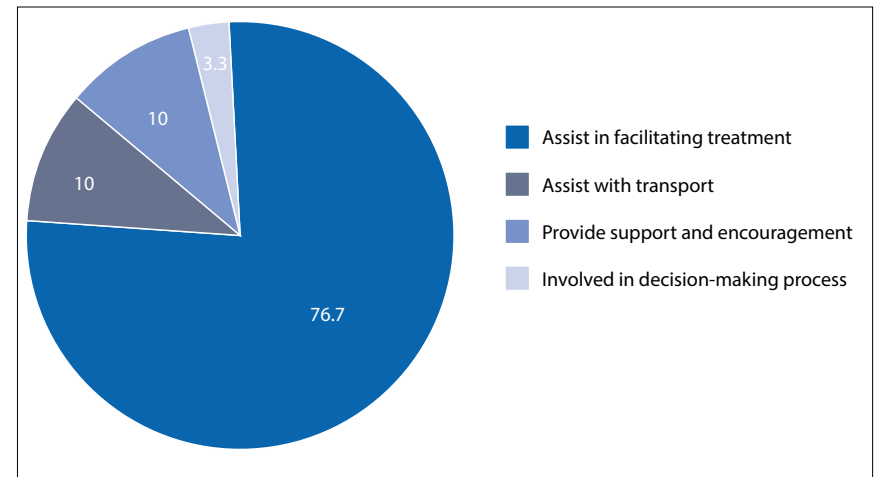

Fig. 7. Roles family members play in treatment $(\mathrm{N}=30)$.

highlighted that parents perceived treatments as being expensive, not easily accessible, and viewed some treatments as more effective than others. Parents were not informed of options pre treatment, or did not receive guidance regarding available evidence-based treatments and facilities. In this study, most parents stated that they had a good relationship with their healthcare professional. The parents also ranked their knowledge of SLT as highest compared with other treatments, reporting that it was the most effective treatment.

These findings should motivate healthcare professionals involved in ASD diagnosis and management to advocate the provision of information and guidance regarding the range of ASD treatments, and to improve access to appropriate facilities through public service treatment provision. Professionals should acknowledge the use of combination treatments including established, emerging, unestablished or controversial treatments. Professionals should be aware of information overload and factor in overlapping treatments, e.g. SLT and picture exchange communication system (PECS), treatments for comorbid conditions, and psychopathology. Ultimately, the type of treatment is affected by the child's age and by the cultural and linguistic background of the family e.g. internet access and the availability of treatments in the child's first language, which is complicated in the SA context. Therefore, it is imperative that healthcare professionals engage in continuing professional education to update their knowledge on the latest evidence-based treatments

Acknowledgements. None.

Author contributions This article is based on an Honours study conducted by VW, SG, NS and KW, who were supervised by JP, with conceptual and writing input from SK.

Funding. None.

Conflicts of interest. None.

1. American Psychiatric Association. Diagnostic and Statistical Manual of Mental Disorders DSM-IV-TR (text revised). Arlington: APA, 2000.

2. Wilczynski S, Green G, Ricciardi J, et al. National Standards Report: The National Standards Project: Addressing the Need for Evidence-based Practice Guidelines for Autism Spectrum Disorders. Randolph: The National Autism Center, 2009.

3. Wetherby AM, Woods JU. Developmental approaches to treatment. In: Chawarska K, Klin A, Volkmar FR, eds. Autism Spectrum Disorders in Infants and Toddlers: Diagnosis, Assessment, and Treatment. London: The Guilford Press, 2008:170-206.

4. Peloquin LJ. Connecting with your child through DIR: The Developmental, Individual Difference, Relationship Based Approach. In V. Zysk, ed. The Best of Autism Digest Magazine volume 1. Texas: Future Horizons Inc., 2005.

5. Gutstein SE. Autism Aspergers, Solving the Relationship Puzzle: A New Developmental Program that Opens the Door to Lifelong Social and Emotional Growth. Texas: Future Horizons Inc., 2000.

6. Koegel LK, Koegel RL, Fredeen RM, Gengoux GW. Naturalistic behavioral approaches to treatment. In: Chawarska K, Klin A, Volkmar FR, eds. Autism Spectrum Disorders in Infants and Toddlers: Diagnosis, Assessment, and Treatment. London: The Guilford Press, 2008;207-242. 
7. Skinner BF. The experimental analysis of operant behavior. In: Rieber RW and Salzinger K, eds Psychology: Theoretical-historical Perspectives. New York: Academic Press, 1980:190-202.

8. Prior M. Intensive behavioural intervention in autism. J Paediatr Child Health 2004;40(9-10):506-507. https://doi.org/10.1111/j.1440-1754.2004.00453.x

9. Smith TR, Wick JE. Controversial treatments. In: Chawarska K, Klin A, Volkmar FR, eds. Autism Spectrum Disorders in Infants and Toddlers: Diagnosis, Assessment, and Treatment. London: The Guilford Press, 2008:243273.

10. Robledo SJ, Ham-Kucharski D. The Autism Book: Answers to Your Most Pressing Questions. New York: Penguin Group, 2005:4-7.

11. Prior M, Roberts JM, Rodger S, Williams K, Sutherland R. A Review of the Research to Identify the Most Effective Models of Practice in Early Intervention for Children with Autism Spectrum Disorders. Australian Government Department, FaHCSIA, 2011.

12. Oono IP, Honey EJ, McConachie HH. Parent-mediated early intervention for young children with autism spectrum disorder (ASD). Cochrane Rev J 2013;8(6):2380-2479 https://doi.org/10.1002/ebch.1952

13. Dymond SK, Gilson CL, Myran SP. Services for children with autism spectrum disorders. J Disabl Policy Stud 2007;18(3):133-147. https://doi.org/10.1177/10 442073070180030201

14. Goin-Kochel RP, Myers BJ, Mackintosh VH. Parental reports on the use of treatments and therapies for children with autism spectrum disorders. Res Autism Spectr Disord 2007;1(3):195-209. https://doi.org/10.1016/j. rasd.2006.08.006

15. Mackintosh VH, Goin-Kochel RP, Myers BJ. "What do you like/dislike about the treatments you're currently using?" A qualitative study of parents of children with autism spectrum disorders. Focus Autism Dev Disabl 2012;27(1):51-60.. https://doi.org/10.1177/1088357611423542

16. Smith T. Outcome of early intervention for children with autism. Clin Psychol Sci Pract 1999;6(1):33-49. https://doi.org/10.1093/clipsy.6.1.33

17. Cimera RE, Cowan RJ. The costs of services and employment outcomes achieved by adults with autism in the US. Autism 2009;13(3):285-302. https:// doi.org/10.1177/1362361309103791

18. Sansosti FJ, Lavik KB, Sansosti JM. Family experiences through the autism diagnostic process. Focus Autism Dev Disabl 2012;27(2):81-92. https://doi. org/10.1177/1088357612446860
19. Lanners R, Mombaerts D. Evaluation of parents' satisfaction with early intervention services within and among European countries: Construction and application of a new parent satisfaction scale. Infants Young Children 2000;12(3):61-70. https://doi.org/10.1097/00001163-200012030-00009

20. Rodger S, Keen D, Braithwaite M, Cook S. Mothers' satisfaction with a home based early intervention programme for children with ASD. J Appl Res Intellect Disabl 2008;21(2):174-182. https://doi.org/10.1111/j.1468-3148.2007.00393.x

21. Bowker A, D’Angelo NM, Hicks R, Wells K. Treatments for autism: Parental choices and perceptions of change. J Autism Dev Disord 2011;41(10):13731382. https://doi.org/10.1007/s10803-010-1164-y

22. Deyro MC, Simon EW, Guay J. Parental awareness of empirically established treatments for autism spectrum disorders. Focus Autism Dev Disabl 2016;31(3):184-195. 10.1177/1088357614559210

23. Shyu YI, Tsai JL, Tsai WC. Explaining and selecting treatments for autism: Parental explanatory models in Taiwan. J Autism Dev Disord 2010;40(11):1323-1331.

24. Statistics South Africa (SSA). Census 2011 Statistical release. Pretoria: SSA, 2012:17.

25. DMNSY Principal Investigators. Prevalence of autism spectrum disorder among children aged 8 years - Autism and developmental disabilities monitoring network, 11 sites, United States, 2010. MMWR 2014;63(2):1-21.

26. Green VA, Pituch KA, Itchon J, Choi A, O'Reilly M, Sigafoos J. Internet survey of treatments used by parents of children with autism. Res Dev Disabl 2006;27(1):70-84. https://doi.org/10.1016/j.ridd.2004.12.002

27. Patten E, Baranek GT, Watson LR, Schultz B. Child and family characteristics influencing intervention choices in autism spectrum disorders. Focus Autism Dev Disabl 2013;28(3):138-46. https://doi.org/10.1177/1088357612468028

28. Mire SS, Gealy W, Kubiszyn T, Burridge AB, Goin-Kochel RP. Parent perceptions about autism spectrum disorder influence treatment choices. Focus Autism Dev Disabl 2015:1-14. https://doi.org/10.1177/1088357615610547

29. Matson JL, Adams HL, Williams LW, Rieske RD. Why are there so many unsubstantiated treatments in autism? Res Autism Spectr Disord 2013;7(3):466474. https://doi.org/10.1016/j.rasd.2012.11.006

30. Senel HG. Parents' views and experiences about complementary and alternative medicine treatments for their children with autistic spectrum disorder. J Autism Dev Disord 2010;40(4):494-503. https://doi.org/10.1007/s10803-0090891-4 